the trial were unable to discriminate between treatment and placebo groups after four to eight weeks of treatment. That this was not due to a high incidence of placebo reactors is shown by the analysis of the objective tests-for example, daily PEFR recordings-and by the final outcome of the trial. It may, however, be a reflection of subjective improvements registered by the moderate initial decrease in daily record scores even in those subjects who later failed (Fig. 2). The failure of the physicians to approach objectivity even in a double-blind trial is not easy to explain, but may reflect the undue attention which is paid by physicians to the patient's (or parent's) history and a desire to give the current treatment regimen the "benefit of the doubt." It shows clearly that open assessment trials in asthma should be interpreted with great caution. Unfortunately, open assessment seems to have been the format of previous long-term clinical trials of D.S.C.G. which have been carried out with asthmatic children. Success rates varying from 38 to $100^{\circ}$, have been claimed.

It is concluded from the present study that D.S.C.G. alone can provide worth-while treatment for $50^{\circ}{ }_{\circ}^{\prime}$ of severe asthmatic children who would otherwise undoubtedly have needed corticosteroid therapy, in the absence of any important side- effects and with no evidence of tolerance over the first 12 months of treatment. A further $21 \%$ may be expected to remit over the course of one year with bronchodilator therapy alone.

\section{References}

Chai, H., Purcell, K., Brady, K., and Falliers, C. J. (1968). Gournal of Allergy, 41, 23.

Chen, L. J., Moore, N., Norman, P. S., Van Metre, T. E., and Baltimore, M. D. (1969). fournal of Allergy, 43, 89.

Connolly, N., and Godfrey, S. (1970). Fournal of Asthma Research, 8, 31.

Falliers, C. J., McCawn, W. P., Ellis, E. F., and Chai, H. (1966). Fournal of Allergy, 37, 1 .

Godfrey, S., Kamburoff, P., and Nairn, J. (1970). British fournal of Diseases

of the Chest, 64, 15.
Howell, J. B. L., and Altounyan, R. E. C. (1967). Lancet, 2, 539.

Jones, R. S. (1966). British Medical fournal, 2, 972.

Jones, R. S., and Blackhall, M. I. (1970). Archives of Disease in Childhood, 45,49 .

Kennedy, M. C. S. (1969). British Fournal of Diseases of the Chest, 63, 96.

Robertson, D. G., Epstein, S. W., and Warrell, D. A. (1969). British Medical fournal, $\mathrm{i}, 552$.

Scadding, J. G. (1966). Lancet, 1, 701.

Silverman, M., and Anderson, S. D. (1972). Archives of Disease in Childhood. In press.

Smith, J. M., and Devey, G. F. (1968). British Medical fournal, 2, 340.

Toogood, J. H., Lefcoe, N. M., Rose, D. K., and McCourtie, D. R. (1971). American Review of Respiratory Diseases, $104,323$.

Williams, H., and McNicol, K. N. (1969). British Medical fournal, 4, 321.

\title{
Implementation of the Abortion Act: Report on a Year's Working of Abortion Clinics and Operating Sessions
}

\author{
A. E. R. BUCKLE, MARY M. ANDERSON
}

British Miedical fournal, 1972, 3, 381-384

\section{Summary}

The results of the first year's working of abortion clinics and operating sessions are reported. Seventy-eight per cent. of patients were managed on the basis of day admission and $20^{\circ}$, were able to leave the hospital within four hours, operation having been carried out by either Karman catheter or by Bierer suction curette under paracervical block. These results were possible because of quick reference of patients to the clinics and the absence of delay in admission for operation.

The measures detailed go some way towards managing the abortion problem within the hospital service; similar arrangements could be instituted elsewhere by the responsible regional hospital boards.

\section{Introduction}

The introduction of the Abortion Act 1967 was not accompanied by the provision of extra facilities for its implementation. The expected rise in requests for abortion which followed quickly led to congestion of gynaecological clinics, an increase in waiting time for outpatient appointments, and difficulties with accommodation of cases, both in the wards and on routine operating lists. Although in theory there is no need to separate abortion referrals from other gynaecological appointments in practice there is much to commend this as it is easier for the gynaecologist to concentrate on similar problems throughout one session

Department of Obstetrics and Gynaecology, Lewisham General Hospital, London S.E.13

A. E. R. BUCKLE, F.R.C.s., F.R.c.o.G., Consultant

MARY M. ANDERSON, M.R.C.o.G., Consultant rather than to have them recurring between other referrals. In addition there is special need to deal with these cases as soon as practicable so that operation can, if possible, be carried out by the vaginal route. Similarly if patients are confined to operating lists set aside for abortions only it becomes easier to manage them from both nursing and medical points of view.

Bearing this in mind, and with the object of minimizing the additional strain which had been placed on the medical and nursing personnel of one specialty, we decided to reconsider the whole question of management of abortion referrals in our group. We suggested to our regional hospital board that abortion clinics should be set up and that abortion operating sessions should be arranged. After discussion it was agreed that two abortion clinics should be held weekly, these to be staffed by consultant gynaecologists, and that there should be one operating session weekly to be shared by two consultant gynaecologists, with a consultant anaesthetist in attendance. Furthermore, the board agreed to additional nursing establishment to allow for cover for the clinics, the operating theatres, and in the wards. The last mentioned was of particular importance, for most of the patients are dealt with as day admissions and this places a strain on general gynaecological wards. It has to date been impossible for us to set up a day case unit, and we have therefore been forced to use sections of the main wards set aside specifically for the purpose of day admission, as outlined below.

Despite these difficulties the patients have been accommodated, much credit going to the unfailing good will and forbearance of the nursing staff of the wards and the operating theatres, who have been prepared to make the scheme work smoothly.

It is with the results from the first year's working of these clinics and operating sessions that this paper is concerned.

\section{Clinics}

These are held twice weekly in the hospital antenatal clinic in the early evening. Patients who are referred for possible abortion 
are given the next available appointment, and it is exceptional for any patient to have to wait more than five days to be seen. Patients are referred either by their general practitioner or by one of our colleagues within the hospital group. On occasions patients are referred direct from local authority family planning clinics or from the hospital family planning clinics. We have in the past made it clear to colleagues in general practice that they are in the strongest position to judge a request for abortion. We have asked them to make their recommendation clear and to forward the duly completed green sheet with the referring letter. If we are in agreement with the request no further reference of the patient is necessary, and we have consequently been spared the hypocrisy of referring patients for a psychiatric opinion merely in order to gain a second signature. In turn this has been reflected in the limited number of patients referred from the psychiatric service; those cases so reaching the abortion clinics are usually ones who have already been attending for psychiatric care. Where a practitioner is not prepared to sign a green form the patient has been seen by a gynaecologist colleague in the hospital.

We have restricted the reference of National Health Service cases to patients living in the maternity catchment area of the hospital. Patients outside the area who are currently attending another department of the hospital are accepted, for it is unreasonable for such patients to be transferred to another hospital where nothing is known of the history. We try to limit the numbers of new patients to six at each clinic, but this number is varied at the discretion of the gynaecologist.

\section{PROCEDURE}

The patient is interviewed and examined, the gynaecologist carrying out examination of the heart, blood pressure, chest, abdomen, and pelvis. A cervical smear is taken for cytological examination; smears may be taken from the urethra and cervix to exclude neisserian infection. Blood is taken for haemoglobin estimation, determination of blood group and rhesus factor, and, where necessary, haemoglobin genotype.

In certain instances the patient is referred for psychiatric assessment and in others for social assessment; generally we have accepted the recommendation of colleagues in general practice, and the decision regarding termination is made at the time of interview. Where it is not advised or the patient has declined to have it carried out arrangements are made for the patient to attend either her own doctor or the hospital clinic for antenatal care.

Where operation is advised the patient is given a printed sheet outlining the particular method that will be used and is told to which ward to report, on which day, and at what time. She signs the consent form, and the preoperative medication is written up and the postoperative therapy arranged. Finally, contraception is discussed and the means of obtaining it decided on. In the case of oral contraception the patient is either given a prescription so that she can bring into hospital her first month's supply or she is given a supply on leaving hospital or she attends her family doctor. In the case of the intrauterine device this may be inserted at the time of operation; alternatively the patient is given an appointment at either the hospital family planning clinic or a local authority clinic for insertion of the device at a later date. Barrier methods may be advised and appointments made at the clinics mentioned. Some patients are referred to the Brook Advisory Centre clinic at the hospital.

Where sterilization is to be arranged the husband will go to his family doctor for reference for vasectomy. For the woman we now in general avoid sterilization at the time of abortion, preferring to bring the patient back in some six weeks for operation via the laparoscope.

\section{Admission Arrangements}

Patients for vaginal termination are instructed to report to the gynaecological ward in question at 08.00 hours on the day of operation, having starved from midnight. Where operation is to be carried out by Karman* catheter or where it is to be carried out by Bierer metal suction curette under paracervical block no premedication is given. In the remaining patients, after premedication with Omnopon $10 \mathrm{mg}$ and scopolamine $0.2 \mathrm{mg}$ the patient is given, in the anaesthetic room, intravenous diazepam $10 \mathrm{mg}$, pentazocine $30 \mathrm{mg}$, and methohexitone sodium $100 \mathrm{mg}$ together with ergometrine $0.5 \mathrm{mg}$, a technique described previously (Loung, Buckle, and Anderson, 1971). All arrangements having been made before admission, there is no need for the patient to be seen by a doctor before being taken to the anaesthetic room.

\section{Operating Session}

Generally we try to have not more than eight cases at each session, any in excess of this being accommodated on other lists.

Vaginal Termination.-The technique employed for vaginal termination has been described (Buckle, Anderson, and Loung, 1970; Loung et al., 1971). It has been modified slightly in that we prefer a higher vacuum pressure of $700 \mathrm{~mm} \mathrm{Hg}$ or more with the Karman suction catheter and we avoid the use of vulsellum forceps by using Allis forceps for grasping the cervix. Where paracervical block is used $5 \mathrm{ml}$ of $1 \%$ lignocaine is injected at each of four points. At the completion of operation the patient is returned to the recovery area and given 5 units of oxytocin injection (Syntocinon) intramuscularly. If she is rhesus-negative $50 \mu \mathrm{g}$ of anti-D immunoglobulin is given on return to the ward.

Saline Termination.-Where termination is to be carried out by intra-amniotic hypertonic saline no premedication is given. The procedure may be carried out either in the ward or in the operating theatre, although we favour the latter. After insertion of a catheter the abdomen is painted with iodine solution and the area draped. A $9 \mathrm{~cm}, 18$ gauge Luer-lok spinal needle is inserted through a skin weal of $1 \%$ lignocaine into the amniotic cavity and a free flow of liquor observed. Five millilitres of indigo carmine solution is injected and the urine is checked for the presence of dye, which would indicate the inadvertent insertion of the needle into the bladder. Eighteen per cent. saline solution is then injected after removal of some $50 \mathrm{ml}$ of liquor, the position of the needle being checked at intervals by the free return of coloured liquor. Finally, an ampoule of Crystamycin is injected and the needle withdrawn. An average of $200 \mathrm{ml}$ of saline is injected and intravenous oxytocin begun immediately, 50 units in $500 \mathrm{ml}$ of $5^{\circ} \%$ dextrose, this being increased to 100 units per bottle until contractions start. A strict intake and output chart is kept and intravenous frusemide given if there is any fall in urinary output. On average the injection-abortion interval has been 20 hours.

Prostaglandin $F_{2} x$. - This has been used by the intrauterine, extra-amniotic route in certain cases, an average of $5 \mathrm{mg}$ being given. There have been no failures with the technique, but as this is not available as a general method for the induction of midtrimester abortion it is not described further.

Abdominal Hysterotomy.-Occasional cases have been managed by abdominal hysterotomy with or without sterilization.

The various methods used are shown in Table I.

\section{Discharge Arrangements}

After return to the ward from the recovery area patients in whom termination has been carried out by Karman curette or by Bierer curette under paracervical block are normally allowed home two or three hours later. Patients terminated by the vaginal route under general anaesthesia are allowed out in the evening of 
TABLE I-Method of Management in the 440 Cases Recommended for Termination

Karman catheter ... .. ...

Bierer suction curette (pareral anaesthesia)

Intra-amniotic hypertonic saline

Prostaglandin $\mathrm{F}, \alpha$

Hysterotomy (with or without sterilization)

Hysterectomy

Aborted spontaneously before admission

TABLE II-Analysis of Patients Seen at Abortion Clinics

Total clinic appointments

Failed to attend

Total patients seen
Not pregnant

Decided against termination

Total patients considered

Grounds inadequate or pregnancy over 20 weeks

Total patients recommended termination

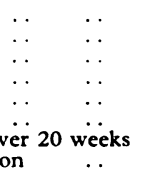

$\begin{array}{ll}\cdots & \cdots \\ \cdots & \cdots \\ \cdots & \cdots \\ \cdots(100 \%) \\ \cdots(92 \%)\end{array}$

503

20

440

the same day. We insist that both groups of patients are accompanied at the time of discharge.

Midtrimester abortion cases cannot be managed by fixed routine as the time of abortion is not certain. In general they are allowed out 24 to 48 hours after abortion.

Outpatient Follow-up.-As mentioned above arrangements for contraception are made at the time of initial interview and we follow up only selected patients. It has not been our experience that patients have been worse off by our adopting early discharge, despite the comment in a circular from the Department of Health and Social Security (1971) that overnight stay is advisable. Some patients have had to be readmitted with abdominal pain, pyrexia, or continued bleeding, but the numbers have been very small in relation to the whole, and we have not felt the need to change the policy.

\section{Results}

The number of clinic appointments made and the number of patients who attended are shown in Table I. Of these 477 were considered for termination of pregnancy and operation was recommended in $440(92 \%)$.

The indications for termination and age and marital status are shown in Tables III and IV. Blood loss in relation to parity and period of gestation is shown in Table $\mathrm{V}$, and again emphasizes the value of termination in early pregnancy. As can be seen from Table VI, most of the patients were managed on a day case basis. Reasons for a stay over 72 hours are stated, and complications are shown in Table VII.

TABLE III-Indication for Therapeutic Abortion in the 440 Cases

\section{Obstetric}

"At-risk" fetus

\begin{tabular}{r|l}
4 & Social \\
10 & Psychiatric/social \\
2 & Psychiatric
\end{tabular}

\section{Discussion}

The patients in this series were managed in large measure on a day case basis; $20 \%$ were managed without general anaesthesia and were allowed home within four hours of admission. We previously reported on a large series of abortions by vacuum aspiration (Loung et al., 1971) where almost $75 \%$ of the patients were discharged home the same day. Another large series of outpatient terminations were reported by Strausz and Schulman (1971) and a smaller series by Lewis, Lal, Branch, and Beard (1971). In all these papers the low complication rate was emphasized; in contrast, much higher complication rates were reported by Sood (1971) and by Stallworthy, Moolgaoker, and Walsh (1971). The British Medical fournal (1971) emphasized the safety of vacuum aspiration as an outpatient procedure, and the Lancet (1971) discussed the varying rates recorded, emphasizing that not all series had high complication rates. We feel simply that our low complication rate is directly related to the small delay between the patients reporting to their doctors and being admitted for operation, so that a high percentage of the pregnancies are not far advanced at the time of termination. Further, operation has been carried out by three doctors only, two consultants and one senior registrar, so that the patients have been managed by a small number of highly experienced personnel.

In regard to subsequent contraceptive management of these patients, this is easily obtained in our hospital family planning clinics. These services have been introduced over the past seven years and represent part of a vigorous campaign on family limitation. In addition our liberal attitude towards female sterilization has been running over a similar period of time, and the rate on both postpartum and general gynaecological patients is some three times higher than the national average. These figures together with the detailed account of methods and results have been published elsewhere (Buckle and Loung, 1971).

Since the Abortion Act became law there has been a steadily increasing demand for abortion and much emotive criticism, both of the Act and of its working. Nevertheless, there is increasing awareness at both national and international levels of the population problems, and various groups are springing into existence to exert pressure nationally to implement measures to curb population increases (British Medical fournal, 1972).

TABLE IV-Age and Marital Status

\begin{tabular}{|c|c|c|c|c|c|c|c|c|c|c|}
\hline & & \multicolumn{8}{|c|}{ Age in Years } & \multirow{2}{*}{ Total } \\
\hline & & 13- & $16-$ & $20-$ & $25-$ & $30-$ & $35-$ & $40-$ & $\geqslant 45$ & \\
\hline $\begin{array}{ll}\text { Single } & \ldots \\
\begin{array}{l}\text { Married } \\
\text { Divorced, }\end{array} \text { separated, } \\
\text { widowed }\end{array}$ & $\begin{array}{l}\cdots \\
\cdots \\
\cdots\end{array}$ & 11 & $\begin{array}{r}94 \\
4 \\
1\end{array}$ & $\begin{array}{l}66 \\
38 \\
11\end{array}$ & $\begin{array}{l}17 \\
55 \\
14\end{array}$ & $\begin{array}{l}12 \\
45 \\
15\end{array}$ & $\begin{array}{r}1 \\
34 \\
5\end{array}$ & $\begin{array}{r}15 \\
2\end{array}$ & & $\begin{array}{r}201 \\
191 \\
48\end{array}$ \\
\hline Total & $\ldots$ & 11 & 99 & 115 & 86 & 72 & 40 & 17 & & 440 \\
\hline
\end{tabular}

TABLE V-Blood Loss in Relation to Parity and Period of Gestation

\begin{tabular}{|c|c|c|c|c|c|c|c|c|c|c|c|c|c|c|}
\hline \multirow{3}{*}{\multicolumn{2}{|c|}{$\begin{array}{l}\text { Period of } \\
\text { Gestation } \\
\text { in Weeks }\end{array}$}} & & \multicolumn{12}{|c|}{ Blood Loss (ml) } \\
\hline & & & \multicolumn{2}{|c|}{100} & \multicolumn{2}{|c|}{$100-200$} & \multicolumn{2}{|c|}{$200-300$} & \multicolumn{2}{|c|}{$300-400$} & \multicolumn{2}{|c|}{$400-500$} & \multicolumn{2}{|c|}{$>500$} \\
\hline & & & P. & M. & $\mathbf{P}$. & M. & P. & M. & P. & M. & P. & M. & P. & $\mathbf{M}$. \\
\hline $\begin{array}{r}4-6 \ldots \\
6-8 \ldots \\
8-10 \\
10-12 \\
12-14\end{array}$ & $\begin{array}{l}\cdots \\
\cdots \\
\cdots \\
\cdots\end{array}$ & $\begin{array}{l}\ldots \\
\cdots \\
\cdots \\
\cdots\end{array}$ & $\begin{array}{r}2 \\
58 \\
31 \\
14 \\
6\end{array}$ & $\begin{array}{r}1 \\
103 \\
113 \\
47 \\
12\end{array}$ & $\begin{array}{r}1 \\
15 \\
1\end{array}$ & $\begin{array}{r}3 \\
11 \\
6 \\
2\end{array}$ & $\begin{array}{l}2 \\
2\end{array}$ & $\begin{array}{l}1 \\
1\end{array}$ & & $\begin{array}{l}1 \\
1\end{array}$ & & 1 & & 2 \\
\hline Tota & .. & 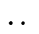 & \multicolumn{2}{|c|}{387} & \multicolumn{2}{|c|}{39} & \multicolumn{2}{|c|}{6} & \multicolumn{2}{|c|}{2} & & 1 & \multicolumn{2}{|c|}{2} \\
\hline
\end{tabular}

Three patients who aborted before admission are not included.

$\begin{array}{ll}\text { P. = Primigravid. } & \text { M. = Multigravid. }\end{array}$

TABLE VI-Duration of Hospital Stay (Vaginal Terminations)

24 hours or less

24-48 hours

48-72 hours

*Uterine perforation 3 , pyrexia 5 , repeat curettage 2 , sterilization 4

TABLE VII-Complications Encountered

Uterine perforation

Postoperative pyrexia

Incomplete evacuation

Haemorrhage in excess of $300 \mathrm{ml}$

Manual removal of placenta (saline terminations)

Evacuation of retained products (Prostaglandin $\mathrm{F}_{2} \alpha$ ) * Managed by abdominal hysterotomy and suture of perforation. One perforated by sterilization-managed by suture of perforation sterilization-managed by suture of perforation.
+ Includes four patients readmitted with pyrexia. \$Both cases readmitted for re-evacuation. 
Despite widespread availability of contraception, however, fertility control is not adequate without additional measures to deal with unwanted pregnancies. This has remained true throughout the world and is most certainly true of the United Kingdom. It seems inevitable that abortion on request will be demanded, probably until such time as general sex education is instituted from primary school age onwards and until a sexually mature population can be made socially responsible in the context of family limitation.

It must be remembered that varying attitudes to abortion will lead to different interpretations of the Act and consequently variable abortion rates in different regions. It is our responsibility to see what measures can be taken to ensure that this increased demand can be absorbed into the existing hospital framework, noting in the process additional staff and accommodation required.

While accepting that additional work can lead to delays in outpatient appointments and a lengthening waiting list, we would point out that with the setting up of abortion clinics and operating sessions as outlined there need be no such problem, for we have a negligible waiting list despite this increase in numbers of patients seen.

In the report of a working party of the Royal College of Obstetricians and Gynaecologists (1972) it was suggested by respondents that special units could be set up to deal with abortion cases alone. The outcome of the deliberations on the working of the Abortion Act by the Lane committee are awaited, but it appears that many centres are realizing the need for separate abortion facilities within the hospital environment. The burden of additional admissions will fall on the nursing staff of the gynaecological wards and the operating theatres. It can be argued that a rising therapeutic abortion rate will be followed by a decreasing septic abortion rate, and it may also be expected that there will be a fall in maternity bookings, so freeing nursing staff of one section to help in the other. Obvious hostility has been met in this latter context and is likely to continue until such time as direction is forthcoming regarding interchange of nursing roles between the obstetric and gynaecological services. Despite this we have shown that the working of an abortion unit within a general hospital can be successfully implemented without dislocation of the normal gynaecological service. It can never be entirely successful without the use of day beds, and we hope that this report will stimulate the introduction of such units within the service.

It is with great pleasure that we acknowledge the far-sighted approach of the South East Metropolitan Regional Hospital Board in agreeing to the provision of, and financial responsibility for, these abortion clinics and operating sessions. The nursing staff of the gynaecological wards and operating theatres at Lewisham Hospital and St. John's Hospital deserve the highest praise in cooperating to make the scheme work successfully.

We are indebted to the Upjohn Company for the supply of prostaglandin $\mathrm{F}_{2} \alpha$ used in some of the patients.

\section{References}

British Medical fournal, 1971, 4, 382.

British Medical fournal, 1972, 2, 65.

Buckle, A. E. R., Anderson, Mary M., and Loung, K. C. (1970). British

Medical fournal, 2, 456.
Buckle, A. E. R., and Loung, K. C. (1971). Fournal of Biosocial Science, 3, 289.

Department of Health and Social Security (1971), E/A223/8, 18 October. Lancet, 1971, 2, 1239.

Lewis, Stella C., Lal, Shirley, Branch, B., and Beard, R. W. (1971). British Medical fournal, 4, 606.

Loung, K. C., Buckle, A. E. R., and Anderson, Mary M. (1971). British Medical fournal, 4, 477.

Royal College of Obstetricians and Gynaecologists (1972). Unplanned Pregnancy. London, R.C.O.G.

Sood, S. V. (1971). British Medical fournal, 4, 270.

Stallworthy, J. A., Moolgaoker, A. S., and Walsh, J. J. (1971). Lancet, 2 1245.

Strausz, I. K., and Schulman, H. (1971). Obstetrics and Gynecology, 38, 199.

\title{
Ultrasonic Fetal Cephalometry: Percentiles Curve
}

\author{
P. FLAMME
}

British Medical fournal, 1972, 3, 384-385

\section{Summary}

Measurements by ultrasound of the biparietal diameter of the fetal head during pregnancy are a reliable guide to fetal growth. As a ready means of comparison with the normal we constructed from 4,170 measurements in 1,394 cases a curve showing the percentiles distribution of biparietal diameters for each week of gestation.

\section{Introduction}

Ultrasonic fetal cephalometry has been practised for nearly 12 years (Donald and Brown, 1961). Willocks et al. (1964) showed that there was a correlation between birth weight and the ultrasonic measurement of the biparietal diameter before birth, and others have used the technique for measuring fetal

Free University of Brussels, Belgium

P. FLAMME, M.D., Assistant, Obstetric and Gynaecological Clinic

growth (Thompson et al., 1965). Also serial measurements of the growth rate of the biparietal diameter have shown it to be related to fetal maturity (Willocks et al., 1967).

The fetal biparietal diameter is measured as a guide to fetal development in most cases in the obstetric department of our hospital. At first a table giving the mean of biparietal diameters for each week of gestation was used as the standard of reference. We then thought it would be better to use a curve showing normal biparietal diameters expressed in terms of their percentiles distribution for each week of gestation. This paper describes how we constructed such a curve.

\section{Method and Results}

For the past five years we have used the A scan and B scan in combination in ultrasonic fetal cephalometry (Campbell, 1968). The measurements in millimetres of the biparietal diameters for each fetus are entered on a punched card with 32 spaces, the first for the serial number of the pregnancy and the remainder for measurements from the 14th to the 44th gestational weeks.

After eliminating all cases complicated by toxaemia, diabetes, or rhesus incompatibility and those in which placental insufficiency was suspected, measurements from 1,394 normal pregnancies were available for study. All the pregnancies ended 